\title{
Desafios epistemológicos para o pensamento socioambiental contemporâneo: a produção do conhecimento institucional e sua relação com os demais saberes e práticas $^{1}$
}

\author{
Epistemological challenges for the contemporary socio-environmental thinking: the production \\ of institutional knowledge and its relation to other knowledge and practices
}

Dimas Floriani $^{2}$

Bom dia a todos e a todas!

Para mim é uma imensa satisfação finalmente poder estar aqui com todos e todas, uma vez que eu já havia sido convidado anteriormente, mas por razões circunstanciais de saúde eu não pude naquela oportunidade estar presente e tive que adiar por muito tempo todos os compromissos. Mas sempre estava bastante antenado com o projeto de vocês, que realmente é um projeto muito bonito, uma forma de estabelecer novidades.

Eu acredito que este projeto de pós-graduação, discutindo a questão do território e da sustentabilidade, é da maior importância para esta região estratégica do Paraná e do Brasil que é o litoral paranaense. Um projeto que depende de um coletivo que inclusive interage conosco, com professores que interagem com o nosso PPGMADE, que é um programa de pós-graduação em Meio Ambiente e Desenvolvimento, que tem um desenho muito próximo do de vocês. Um desenho de agenciamento da interdisciplinaridade e de métodos e formas de produção do conhecimento bastante diferenciados, pelo menos nas suas intenções, em relação a uma universidade cuja cartografia ainda depende de concepções bastante segmentadas, de uma ciência segmentada, uma ciência unicamente positivista. Por isso que nós defendemos a ideia de uma epistemologia da diversidade e com várias adjetivações porque também a produção do conhecimento é bastante complexa. É um pouco nessa perspectiva que nós vamos trazer algumas reflexões, mas também na dimensão do agenciamento institucional da produção do conhecimento.

Gostaria então de iniciar pelo que em geral nós designamos: falar desde o lugar da enunciação. Pode-se entender a enunciação como aquele momento do enunciado, da apresentação, do discurso, do argumento, mas também como complemento da ação. Desde que lugar do

\footnotetext{
${ }^{1}$ Conferência de abertura do III Seminário de Projetos de Pesquisa do Programa de Pós-Graduação em Desenvolvimento Territorial Sustentável(PPGDTS), da Universidade Federal do Paraná, realizada em 30 de junho de 2016, na cidade de Matinhos (PR).

${ }^{2}$ Professor dos Programas de Pós-Graduação em Sociologia e em Meio Ambiente e Desenvolvimento (MADE), da UFPR. E-mail: floriani@ufpr.br.
} 
conhecimento e da ação nós podemos projetar a imagem que nós temos sobre aspectos do conhecimento, da sua produção e da sua institucionalidade. É por isso que nós vamos sempre acrescentando a essa ideia de uma epistemologia da diversidade uma epistemologia cultural, uma epistemologia híbrida, uma epistemologia política, a relação da ciência com os valores, a relação do conhecimento com a cultura.

Evidentemente que nós estamos no extremo ocidente, até geograficamente. O extremo ocidente é uma categoria como a epistemologia do sul, que não corresponde apenas a uma definição geográfica de lugar. Mas esta epistemologia do sul, ou este extremo ocidente, é reveladora também de uma historicidade, de uma formação social diversa, por exemplo, da outra face da epistemologia do norte ou do núcleo duro do Ocidente. Todos os nossos autores, as nossas referências, a nossa formação, inclusive escolar, se remete a essa epistemologia do norte. Nós temos alguns países chaves que definiram a maneira como nós articulamos e organizamos o conhecimento. Todos os que se formaram e formam aqui, por exemplo, na área de Humanas e de Ciências Sociais, nossos autores de referência são autores europeus, latinos, anglo-saxões ou alemães. E foi neste berço, nesta origem que nós baseamos todas as nossas categorias de análise, a formação do conhecimento científico - que é o legado da modernidade - e a maneira de como nós reproduzimos e formamos o conhecimento é nessa imensa matriz de um pensamento ocidental.

Evidentemente que tudo isso hoje, no limiar do século XXI, responde a uma série de críticas e questionamentos que emergem de diferentes lugares. Se tomarmos, por exemplo, nos anos 1960, um dos epistemólogos que influenciou muito os estudos da inteligência, da teoria do aprendizado, das ciências cognitivas e da própria epistemologia, foi Jean Piaget. Ele mesmo incorporou diversas formações - era biólogo, matemático, psicólogo - e dialogava com diferentes áreas do conhecimento. Num texto muito importante de 1967, Lógica e Conhecimento Científico, que ele organizou com diversas ciências, inclusive as humanas, a economia, a física, a biologia e a cibernética (que era uma ciência emergente que depois teve aplicações na informática e que abriu também um campo novo para as ciências cognitivas), ele inaugura uma coleção que ficou famosa, mais de mil páginas do livro publicado pela coleção Pléiade, da Gallimard da França, em Paris.

Nesse texto, que virou referência, ele vai falar em diversos tipos de produção epistemológica, que o debate sobre o conhecimento e sobre a ciência pode emergir no interior dos próprios cânones da ciência, mas não exclusivamente. Ele fala de dois outros tipos de ordens epistemológicas, que são o que ele chama de ordens paracientíficas e metacientíficas. Questões de ordem filosófica, até de ordem religiosa, de ordem ética, de ordem cultural, podem induzir que nós possamos introduzir de fato no debate da produção do conhecimento; essas questões extracientíficas 
podem, pois, produzir efeitos sobre uma ecologia das práticas científicas, tanto do ponto de vista de sua produção, por pesquisadores, como de seus usos pela sociedade.

Eu acredito que Piaget inaugura um divisor de águas importante e que depois, passados menos de vinte anos, vamos ter a emergência, o aparecimento de autores que desde as ciências estabelecidas e consideradas, no imaginário do reconhecimento das ciências, como ciências centrais ou poderosas, que são as ciências químico-físicas, as ciências da natureza e da vida, porque as ciências mais de ordem matemática já tinham seu estatuto garantido desde os gregos. Na parte da bioquímica e da química, um grande autor chamado Ilya Prigogine, juntamente com uma química e filósofa, Isabelle Stengers, vão dialogar muito com a antropologia, principalmente com a escola francesa de Callon e Latour, e vão escrever um livro paradigmático chamado a Nova Aliança: a nova aliança da ciência com a natureza, a nova aliança da ciência com a cultura. Nesse livro emblemático de 1980 também se reinaugura outra maneira de discutir ciência, através de uma coisa muito simples que os lógicos já haviam indicado, que eles chamavam de argumento de autoridade, embora os autores não estavam querendo impor argumentos duvidosos, usando sua autoridade científica amplamente reconhecida pelos seus pares. Estavam simplesmente exercendo um papel crítico, desde novos argumentos filosóficos, políticos e culturais sobre os novos sentidos da ciência.

A nova crítica filosófica tecida por Deleuze e Guattari, Morin, Atlan, Castoriadis e outros ainda permitia-lhes apresentar fortes argumentos de que a ciência por si mesma é incapaz de fazer sua própria autocrítica e que os antigos paradigmas já não serviam para manter uma visão ufanista sobre o progresso e a razão. A ciência não é tão neutra nem isenta de conflitos e interesses como uma certa epistemologia do objetivismo quer defender. Então nós caímos aí até no campo meio foucaultiano do saber e do poder, mas que vocês sabem pelas práticas nossas que isso existe. Um pouco como Bourdieu diria, que a disputa dos campos na produção da ciência existe evidentemente como disputas em qualquer outro campo. Talvez o campo científico tenha simbologias e linguagens relativamente singulares porque deve corresponder a maneira de como se estabelece no campo as estratégias de distribuição do poder e disputas do poder e de produção do conhecimento.

Contudo, no campo você tem que ser coerente com os cânones desse mesmo campo. Você tem que produzir de acordo com os parâmetros e os cânones daquilo que a comunidade epistêmica estabelece como sendo válido e necessário que se faça. Claro, de vez em quando a gente encontra não o cientista biruta - Thomas Khun dizia que existe também o cientista biruta, esse que fala sozinho, fala coisas interessantes mas fala sozinho, não encontra eco nos seus pares, isso existe, todos nós conhecemos e sabemos que existe e às vezes até é necessário -, mas pessoas que estão fora do eixo também. Essas são pessoas importantes também, tipo Feyerabend. Ele era um 
iconoclasta da ciência, era uma pessoa que não acreditava muito naquilo que todos diziam sobre aquilo que é ciência. Então lá pelos anos 1970 ele foi escrever aquele livro, em 1975, Contra o Método ou um pouco antes, porque naquele momento - vocês notem que o debate sobre produção do conhecimento era datado; hoje, por exemplo, se vocês fizeram curso de Filosofia da Ciência, de História da Ciência, aquele capítulo dos anos 1960, 1970 e até 1980 entra como um capítulo na história do debate epistemológico fortemente marcado por autores tais como Popper, Kuhn, Lakatos, Bachelard, Feyerabend (...), cuja centralidade da ciência era marcadamente modelada pelas ciências duras. O problema é que, a exemplo deste debate, podemos falar também da questão da moda, no sentido não só das preferências ou imposição de certos autores mais lidos, mas também estatístico, ou seja, para onde convergem determinadas tendências. Isso é muito comum no momento em que nós vivemos por etapas, dos autores que são legitimados, dos temas que nós discutimos, dos temas que nós escolhemos para nossas pesquisas. Tudo isso deriva da moda, não no sentido pejorativo; são as grandes tendências que se estabelecem em conjunturas, em determinados momentos -, naquela conjuntura dos anos 1960, 1970 nós também das ciências humanas, das ciências sociais, quando fazíamos debate sobre a ciência, os nossos referenciais eram desse momento, dessa época; passava, por exemplo, pela Estrutura das Revoluções Científicas, pelas obras do Karl Popper, do Lakatos e Polanyi. E o Feyerabend destoava porque ele era, digamos assim, como São Tomé - para quem está próximo da religião católica conhece a figura de São Tomé que tem que colocar o dedo na chaga; quando Cristo ressuscitou ele queria colocar o dedo na chaga, porque ele estava lá na cruz. Essas referências à cruz são interessantes no discurso religioso, são metáforas bastante interessantes.

Anos depois o Humberto Maturana e o Francisco Varela escreveram A árvore do conhecimento, que também foi um desafio epistêmico interessante da Escola de Santiago. Eram autores que vinham da biologia, o Maturana principalmente, o Varela já vinha mais das ciências cognitivas, mas a sua formação básica era a biologia, que foram discutir a questão do conhecimento. Depois se separaram, o Varela faleceu precocemente aos 57 anos, foi dialogar lá na França com o budismo inclusive. Em A árvore do conhecimento eles vão falar de forma metafórica - não sei se alguém de vocês já teve a oportunidade de folhear o livro, mas vale a pena; é um livro bastante instigante se vocês têm preocupações desta ordem, de discutir os fundamentos da construção do conhecimento, a construção de estratégias cognitivas ligadas a matrizes holísticas do conhecimento, bastante influenciados pela teoria dos sistemas, da relação entre organização e estrutura, da autopoiesis e do fechamento estrutural, depois retomados por Niklas Luhmann para analisar os sistemas e subsistemas sociais. Eles usam aquela imagem de algumas pessoas que olham o quadro, 
não sei se de Giotto, pintor do Renascimento, não lembro mais o autor do quadro, mas existem figuras perplexas olhando para Cristo na cruz. Ambos os autores vão dizer o seguinte: o que eles estão expressando naquele olhar perplexo? Eles estariam dizendo o seguinte: "Mas se eu já sabia! Eu já sabia que isso ia acontecer!”. E eles usam essa metáfora como uma presunção, uma imaginação daquilo que ao olharmos, ao vivermos certos fenômenos ou eventos, já estamos num certo sentido emitindo alguma opinião, algum juízo sobre esse evento, sobre o fato, o acontecimento; serve também como uma alegoria à presunção antecipada do conhecer. Essa referência entre o observador e o fenômeno é um capítulo interessante e permanente que desafia todas as concepções ou teorias da gnoseologia, ou do conhecimento. E se aproximarmos este debate nesta virada do século, de fato há toda uma discussão da pós-modernidade do que é um evento, do que é um fato e como se posiciona o sujeito diante disso. Por exemplo, na teoria do sujeito, que é um outro tema central na discussão, na relação sujeito-objeto, alguns filósofos pós-modernos vão dizer que o sujeito não existe, o sujeito se torna sujeito quando ele acontece, como no caso do filósofo francês Alain Badiou. Então você já tem uma discussão sobre historicidade, temporalidade. É bem interessante porque você adota alguns critérios diferentes do sujeito estabelecido. Por sua vez, a discussão sobre o sujeito sofre a influência da psicanálise lacaniana, em que este é visto como um sujeito travado pelo desejo, inconcluso, preso por um real defeituoso; ou então o sujeito é visto como subjugado pelas engrenagens do poder, pelas estruturas disciplinadoras dos aparatos institucionais da modernidade, pela leitura de Foucault e Agamben.

Eu acho que isso aí vai ter consequências também na discussão sobre identidade. Por exemplo, se a gente lê Bauman, é possível imaginar que os sujeitos negociam as suas identidades à medida que vão experienciando, vivendo. Numa escala planetária isso tem efeitos os mais diversos. Hoje, fala-se em dimensões relacionais, tanto do ponto de vista cultural como político. Em sociedades marcadamente heterogêneas como aquelas com forte influência de um passado colonial, como as sociedades latino-americanas, africanas e mesmo asiáticas, não é possível entender as estratégias relacionais entre as pessoas, apenas do ponto de vista da singularidade dos sujeitos como pessoas ou indivíduos. Comunidades tradicionais, indígenas, camponesas ou mesmo um subproletariado urbano vão tecendo suas estratégias relacionais, com base nas suas identidades culturais, muitas vezes à margem do sistema dominante, muitas vezes invisibilizados, mas que se reconstroem por meio de estratégias de resistências. Ora, para colocar esses elementos dessa maneira é necessário elaborá-los teoricamente desde outro olhar e outra lógica que dependem de estratégias de matrizes epistêmicas que nós temos que configurar essa elaboração de diversas maneiras. Considerando ainda essa questão do ponto de vista da relação entre sujeito e objeto, hoje 
já não é nenhum sacrilégio, nenhuma heterodoxia dizer que, por exemplo, não se deve mais separar essas entidades. As teorias da complexidade, por exemplo, de Edgar Morin, vão dizer que realmente nós perturbamos como sujeitos a realidade e somos perturbados por ela. Em Ciência com consciência ele vai nos dizer isso aí.

Essa relação de objetivação do objeto, desculpem o pleonasmo, vai ser muito forte na matriz positivista, que não é única, pois existem diversas vertentes. Uma vez eu acabei criando um mal-estar numa discussão, porque um dos autores de moda no nosso cânone sociológico é o Norbert Elias. Norbert Elias é um positivista assumido, mas ele é um bom positivista. E aí veio a relação do autor com sua obra também - eu sempre digo "quando eu crescer, quando eu ficar grande, quero fazer um estudo sobre o autor e sua obra", mas claro que esse tempo nunca chega e eu deixo como promessa para continuar vivendo, inclusive! Uma vez, num discurso de epistemologia e teoria social, eu sempre trabalhava com alguns autores para ver como eles pensavam a sua própria obra.

O Norbert Elias tem um livrinho interessante que a Zahar traduziu como Elias por ele mesmo e que no fundo são longas entrevistas, várias, são cento e cinquenta páginas de entrevistas em que ele vai falando de sua vida, da concepção de mundo, porque ele era médico e vai fazer revelações interessantes até do uso da medicina para entender os comportamentos físicos dos sujeitos, das pessoas. Norbert Elias teve a mãe e o pai mortos em campo de concentração. Ele foi daquela geração que foi para Paris, com a Hannah Arendt também, com o Albert Hirschman, aquele grupo de intelectuais alemães que se refugiaram em Paris e que depois foram para os Estados Unidos, mas ele não foi para os Estados Unidos, ele foi para Inglaterra. O que me impressionou, uma pessoa tão marcada pelo sofrimento da guerra, do fim do Iluminismo, do berço da cultura vivenciando a barbárie mais extrema - por isso é uma ilusão nossa pensar que a Europa é um continente civilizado, no sentido do que a gente imagina o que é a civilização, pois no fundo lá nós temos sempre um barril de pólvora, as guerras vêm de lá, dessa civilização. Não que nós sejamos pacíficos aqui no extremo ocidente. O projeto civilizacional, que inclusive é um dos temas do Norbert Elias, tem o seu berço na Europa moderna, que é uma Europa cheia de conflitos, de guerras. Impressionante: se você vai para qualquer país europeu, começa a encontrar muitos museus da guerra, museus das armas, porque lá teve muito guerra e muito combate de diversas ordens e natureza. Nós, aqui, que fomos formados com essa cultura ocidental; vocês, aí, dessa geração mais nova, eu não acompanhei mais os currículos escolares, mas a gente era perito em história europeia e da história do Brasil e da América, eram só uma história dos grandes personagens que faziam a história. A gente entrava nos detalhes das guerras religiosas, da Reforma, da Contrarreforma, a gente estudava em detalhes isso aí. Então a gente vê que realmente essa civilização é paradoxal. Às 
vezes a gente fica criando um imaginário do que é uma civilização, uma cultura, a gente fica projetando lá longe o que seria uma história ideal, e a gente esquece de olhar pra gente, pro nosso contexto, a nossa cultura, a nossa própria história.

Enfim, mas o que me impressionava - voltando então a essa dimensão de como cada autor projeta sua obra - o que me chamava muita atenção no Norbert Elias (veja bem, isso não estava no script de minha fala, mas eu acredito muito no momento, as coisas aparentemente sem sentido, podem fazer muito sentido!), o estranhamento absoluto para seu tempo e sua época, para pensar seus temas de pesquisa. É isso que nós estamos também no fundo problematizando, essa relação sujeito e objeto. Talvez se no lugar do objeto colocarmos o Outro, que é o diferente ou o complementar, possamos superar a dicotomia positivista! Mas isso pode nos dizer o seguinte: será que é assim que se faz a teoria? Eu diria que essa é uma possibilidade de se fazer uma teoria, se distanciando do seu tempo. No fundo, Norbert Elias acabou fazendo uma sociologia histórica da civilização europeia, o que não impedia que ele tivesse uma consciência muito grande da maneira de como ele conduzia a sua concepção de ciência e de conhecimento. Em oposição, por exemplo, a Pierre Bourdieu, que antes de morrer produziu um texto que no fundo ele pensou "eu quero pensar o sentido de minha obra”; ele faleceu em 2002 e essa obra foi em 2000, Esboço de autoanálise.

No fundo, Bourdieu foi o autor que durante a vida inteira tentou exorcizar seus fantasmas como alguém que não estava destinado ao campo - dada a imensa resistência do campo acadêmico francês para aqueles que não haviam acumulado certo capital cultural - e que acabou entrando no campo da ciência, pela sua excepcionalidade intelectual. Durante toda a sua vida, sua história, não cessou de tentar exorcizar seus fantasmas: ele que era um plebeu, filho de interioranos lá da Província de Pau, no sul da França, seu pai era um pequeno funcionário dos Correios e a mãe era semianalfabeta, como é que se tornou alguém consagrado na terra em que o vinho, a filosofia, a literatura e o queijo prevalecem como signo de uma história construída por uma sociedade fortemente segmentada, por uma sociedade de corte, da nobreza e de títulos de fidalguia, dos estamentos. Essa segmentação se reproduz até hoje no campo intelectual, no mundo da moda, da alta costura, da arte.

Quando nós discutíamos Ciência como vocação, do Weber, justamente em que se mostravam modelos institucionais de produção do conhecimento, ele comparava universidades dos Estados Unidos com as europeias, especialmente onde o privat dozent prussiano tinha posses suficientes, suas famílias permitiam que atuassem nas universidades sem receber nada, apenas como signo de distinção social e prestígio. Isso caracterizava uma condição cultural, de estamento, de poder simbólico pelo menos, de como foram se estabelecendo as universidades na Europa em 
oposição, por exemplo, às universidades de acesso mais democrático, mais fácil, no qual também a ciência acaba sendo estipendiada, desculpem esse resquício de linguagem, que vive de salário, de renda, como funcionários de universidade, como é o nosso caso; nós nos profissionalizamos como professores, como pesquisadores. Então é possível estabelecer a relação entre o autor e sua obra, independente de se cada um apresenta suas melhores razões sobre si mesmo e seu tempo - porque muitas vezes a gente tem que desconfiar do que nós dizemos de nós mesmos, porque tem toda aquela questão do engano, do autoengano, da racionalização. A gente apaga aquilo que é negativo da vida da gente, da memória da gente, felizmente a memória é nossa aliada em alguns momentos, mas pode ser nossa inimiga em outros -, independente do que cada um diz de si mesmo, somos guiados ou traídos por modelos, muitas vezes de maneira inconsciente. Ainda a respeito do autor e de sua obra, existe todo um histórico de estudos a esse respeito. Um belo exercício sobre esses estudos na área de ciências sociais foi feito pelo sociólogo austríaco, do grupo de estudos de Bourdieu, chamado Michael Pollack, ou ainda por Michael Lowy.

Vocês sabem que trabalham com as tipologias, os exercícios classificatórios, que existem em qualquer área de conhecimento, com o que você ordena a realidade, acaba-se criando tipologias que permitem diferenciarmos por associação, por semelhança e diferença aquilo que se agrupa em determinados segmentos ou se distanciam deles. Então nós temos uma variedade de formas que se alimentam justamente de longos períodos de discussões e debates que se constituem em matrizes do conhecimento, que nós chamamos de metodologias, de teorias. São campos do conhecimento que vão se estabelecendo nas diversas disciplinas que também por razões de ordem institucional vão se estabelecendo, o que acaba constituindo-se em cultura científica. A pergunta nossa é: em que campo nós nos situamos? Desde que lugar da enunciação nós estamos falando quando falamos de determinados temas e produzimos conhecimento?

Essa questão da episteme versus a opinião, a doxa, já estava presente lá na origem do debate filosófico platônico. Em uma de suas obras, Teeteto, Platão vai fazer justamente essa distinção entre aquilo que é do domínio do argumento, da lógica e das experiências de linguagem bem-sucedidas na área do conhecimento, aquilo que entra no campo do argumentável e da troca e da discussão, e que permanece, e daquilo que é do domínio da opinião, que os gregos chamavam de doxa. É isso que nós estamos vivenciando no dia a dia quando discutimos o interinato (governo ad hoc que assumiu a presidência pelo parlamento), o golpe, quando nós torcemos por um time ou outro, quando nos filiamos a determinadas associações laicas ou religiosas, é um domínio, é a morada da doxa, das nossas relações cotidianas com aquilo que é aprendido ou infundido por valores e crenças, por preconceito ou não e não temos muita certeza de sua validade, porque nós operamos com 
determinadas opiniões e valores que funcionam nas estratégias de reconhecimento com determinados grupos sociais, familiares etc.

Tudo isso é da ordem também da metafísica, que é o domínio que estabelece a discussão sobre as origens e a finalidade do conhecimento, da linguagem e de seus usos. Isso me faz lembrar de uma economista inglesa chamada Joan Robinson, que era neokeynesiana e foi professora do Celso Furtado na London School of Economics. Ela escreveu um livro bastante interessante que me impressionou muito lá nos anos que eu li, que chamava Filosofia econômica. Ela trabalha com a questão da metafísica, dos valores, justamente na área de discussão da Economia. A metafísica se remete às origens e ela diz do ponto de vista filosófico, das indagações sobre as crenças, ela dizia assim: "porque eu acredito naquilo que eu acredito ou o que me leva a acreditar naquilo que eu acredito"? Se nós fizermos uma arqueologia das origens das nossas crenças, dificilmente nós vamos chegar a um lugar muito claro, vamos chegar talvez na caverna meio platônica das imagens, das sombras. Esse é um domínio que depois, nas Ciências Sociais, a gente chamou, grosso modo, de "ideologia", em que se vinculam uma série de elementos do não dito, do não explícito. O não dito, o não explícito, ele tem um rigor, uma incidência muito grande na maneira de a gente pensar sobre o mundo, de a gente qualificar o mundo, a realidade. Teorias de explicação sobre os fenômenos ideológicos são muitas vezes concorrentes; há uma série de teorias a esse respeito, inconclusivas, mas que servem para referir-se com alguma propriedade, pelo menos aos fenômenos ou constelações de valores, crenças e ditos sobre o sentido do mundo. Correspondem mais ou menos a um certo Modelo Padrão para a física contemporânea, tão bem explicado pelo físico italiano Carlo Rovelli (em Sete breves lições de física) e que reúne um conjunto de conhecimentos sobre a matéria e o funcionamento do mundo das coisas.

Isso também já constitui por si - essa maneira de a gente identificar esses fenômenos do mundo das ideias, do conhecimento, da linguagem ordinária e do funcionamento dos fenômenos socioculturais -, elementos que nos convidam a nos aproximar racionalmente, buscando entendê-los, ordená-los, para dizer se esses fenômenos correspondem à determinada realidade e a que fatores eles obedecem ou a qual constelação de significados eles correspondem.

Eu lembro também que todo o debate sobre ideologia foi fortemente marcado nos anos 1970 pela escola do marxismo estruturalista, pelo grupo do Althusser, do famoso livrinho dele dos Aparelhos ideológicos do Estado, e me marcou muito uma frase que dizia "a ideologia não tem história”. Ou seja, é muito difícil você dar uma historicidade à ideologia. Isso aí também é bastante discutível, o sentido disso. Mas como Althusser dialogava com os lacanianos, que revisitavam a obra do Freud que diziam não ter o inconsciente uma história. Essa também é uma característica da 
moda: foram grupos de releitura do capital, de releituras do Marx nos anos 1960 que tiveram ecos interessantes na América Latina. A maneira de como seria o marxismo à luz dessas teorias, que na ciência política estava o Poulantzas, que era um grego - os gregos continuam muito presentes na cultura francesa, Castoriadis foi outro autor que influenciou muito o público -, e sempre tinha ecos desse debate e todos nós líamos dessa cartilha. Então, é importante pensar como é que nós nos situamos como pessoas que se identificam com determinadas teorias; como é que nós reproduzimos e qual é o grau de consciência que nós temos daquilo que estamos discutindo em determinado tempo.

Na França tinha a Escola dos Annales também do Marc Bloch, que fez história, Fernand Braudel, que influenciou muito autores que nos influenciam até hoje como Immanuel Wallerstein, da teoria do Sistema-Mundo. Mas tinha um autor que me chamava muita atenção que se chamava George Duby, que era um historiador muito forte sobre história medieval, e logo no prefácio ele trabalhava com a constituição das ordens, dos estamentos, das cavalarias, dos cavaleiros da ordem da espada, dos reinados, dos reis, dos príncipes. Logo na introdução de seu livro As Três Ordens ou o Imaginário do Feudalismo, ele dizia o seguinte: vamos ver o que nós podemos entender por ideologia, ou seja, como é que os medievais representavam a sua cultura, os seus valores, a sua forma de ser. Então ele inverte a fórmula um pouco clássica do marxismo, da teoria reflexo, grosso modo seria o seguinte: eu penso aquilo que eu sou e pelas materialidades da realidade; eu sou no fundo levado a pensar de uma determinada maneira. Duby dizia, então, que a ideologia não é o reflexo da realidade sobre a mente ou a consciência; antes, é a forma de como agimos no mundo. Ou seja, não é tão necessário explicar de antemão em que mundo vivem as pessoas, para depois dizer que elas pensam assim porque são prisioneiras dessa própria realidade, mais ou menos o que repetia Marx: a ideologia dominante é a ideologia das classes dominantes. Isso na verdade é um atalho. Eu não quero ser injusto com essa visão, ela é mais sofisticada, naquilo que o Marx já dizia na Ideologia alemã, e antes também nos Manuscritos filosóficos: é o ser que determina a consciência, não é a consciência que determina o ser. Se vocês pegarem essa pequena frase que rodou o mundo em séculos, ela é muito repetida, é uma maneira de afirmar também o lugar da enunciação: se eu sou mais adepto ao materialismo, se eu sou idealista, um kantiano convicto, um hegeliano, as ideias têm sua independência, elas vagam pelo universo. Embora, ambos, Kant e Hegel, abriram a caixa-preta do pensamento, ninguém há de negar isso, a importância que eles tiveram. Porém, Marx, nos Manuscritos, tem uma passagem bastante interessante sobre o papel do pensamento e da realidade, quando afirma que ser e consciência são diferentes, mas em algum momento se fundem. 
Mas se vocês estenderem essa posição marxiana que aparece com maior evidência na Ideologia alemã ou nas Teses sobre Feuerbach e se vocês cruzarem com visões mais contemporâneas dessa relação do objetivo e subjetivo, da consciência e da realidade, com posições da teoria da complexidade vocês vão ver questões bem interessantes e diversas dessa polaridade. Em A árvore do conhecimento, Maturana e Varela vão falar explicitamente desta questão: o que é o pensamento? O pensamento é como uma máquina fotográfica que registra, ou seja, uma teoria representacionista que eu fixo o que está fora por mecanismos cognitivos, ou a realidade é a projeção de um mundo que já está em mim porque eu estou no mundo? Eles vão dizer: nenhuma, nem outra! Eles chamam a primeira posição de representacionismo e a segunda de solipsismo.

Isso vai ter reflexos na história da filosofia moderna, inclusive aqueles que rejeitam muito a ideia kantiana ou hegeliana que são os ingleses, que são pragmáticos, são práticos, racionalistas, experimentalistas - as teorias do Bacon, do próprio Hume, um dos autores que introduz todo o debate da teoria da indução, embora ele também fosse um adversário da crença ilimitada da indução. A indução é a partir das experiências que eu vou derivando a repetição e aí gero uma teoria geral a partir das experiências acumuladas, que é a base da ciência moderna. Ele também tem uma famosa frase pra gente não ser prisioneiro das ilusões da indução, pelo exemplo do ganso, retomada, parece-me, por Bertrand Russel. Um granjeiro tinha uma criação de gansos e todos os dias ia jogar milho para eles e os gansos faziam festa quando ele chegava. Só que os gansos não olhavam o calendário e chegou o dia 24 de dezembro e eles fizeram festa igualmente como nos outros 364 dias do ano, só que no dia seguinte eles foram para a panela do granjeiro. Então, desconfiem do determinismo de uma teoria da indução que pode nos conduzir a erros também!

Essas estratégias de conhecimento, que estou trazendo de uma maneira bastante desorganizada pra vocês, elas são inspiradoras porque ao mesmo tempo em que elas nos colocam diante de desafios da natureza da lógica do processo de produção do conhecimento, elas se fixam, se instituem. Então, a pergunta que nós podemos fazer a nós mesmos é de que ordem instituída nós estamos falando quando nos referimos a ela? Nós, enquanto sujeitos concretos numa instituição determinada, cuja matriz está estabelecida de uma determinada maneira, cujas filiações estão definidas também. E que disputas se operam a partir dessas identificações e identidades das nossas tribos? A que ordem de filiação nós também respondemos quando estabelecemos grupos de pesquisa, quando nós nos identificamos com um programa de pós-graduação, por exemplo. Claro, vocês vão dizer, há uma diversidade, não há só uma matriz.

Nós operamos com epistemologias plurais, que eu acho que é mais condizente com um mundo em que nós estamos vivendo porque, parafraseando Artur Escobar, que é um antropólogo 
colombiano professor lá em Chaptel Hill, Carolina do Norte, nos Estados Unidos, ele vai falar da ordem do pluriverso. Esse pluriverso não é só epistemológico; ele é da ordem do concreto cultural também. Veja o caso do litoral paranaense. Há uma diversidade tamanha de situações societais, culturais, que seria lamentável se a gente operasse apenas com uma epistemologia ou com uma concepção de conhecimento e com aquela outra parte segunda da enunciação que é a ação, eu considero ação como sendo constituída por sistemas de práticas. Mas só pra fechar antes de entrar no sistema de práticas, só pra fechar a questão, pois eu fui longe demais, e retomando a questão da ideologia que eu estava falando desde a posição de George Duby, ele vai dizer, então, que a ideologia é a maneira de como nós agimos sobre o real, mais do que sendo aquilo que nos leva a agir porque pensamos de uma determinada maneira. Ora, uma coisa está imbricada na outra. Mesmo que então ele estivesse deixando como implícito nessa caixa-preta o campo dos valores, das noções, dos conceitos, das categorias de análise, das justificativas que nós damos pra dizer por que enxergamos o mundo desta ou daquela maneira.

Talvez o recurso que ainda está a nosso alcance na área instituída do conhecimento é aquilo que eu chamo, muitas pessoas chamam, do domínio dos argumentáveis. Eu hoje estou em contato com um filósofo norte-americano, mas que vive no Brasil, na USP, que se chama Hugh Lacey, que é um filósofo analítico. A filosofia analítica tem seus erros e limitações, mas a filosofia analítica se dá ao trabalho de tentar abrir a caixa-preta dos argumentos em torno de um determinado tema. Ultimamente, ele está trabalhando muito com a questão da transgenia, da agroecologia e ele então desconstrói os argumentos tanto daqueles que estão a favor da transgenia como daqueles que fazem uma crítica feroz desde a agroecologia. A filosofia analítica tem essa paciência de estar abrindo as formações discursivas, os argumentos de cada área do conhecimento para testar a ideia da relação entre filosofia e valores, ciência e valores. Claro, então nós estamos trabalhando com estratégias hermenêuticas, interpretativas, e que eu mesmo busquei, não pela filosofia analítica, eu não sou muito simpático à filosofia analítica, mas também com aqueles autores que operam no domínio dos argumentáveis de uma forma diferente ao analítico e muitas das vezes nós deixamos no domínio do subentendido, do não explícito, o ponto de partida dos nossos argumentos. E em domínios de disputas tão ferrenhas tais como esses debates dos transgênicos e dos não transgênicos, é muito provável que o domínio da ciência fechada em si mesma seja incapaz de dar respostas na altura daquilo que nós poderíamos ensejar como algo desejável e até necessário.

É bem interessante este domínio da interpretação analítica, porque é como se nós estivéssemos discutindo se o governo interino deu o golpe ou não deu, se ele é legítimo ou ilegítimo. Vejam a dificuldade porque aqueles que dizem que não há golpe reivindicam os 
mecanismos institucionais e reivindicam como argumento defensável essa maneira de argumentar, de apresentar. Já nós que consideramos que houve golpe, nossa capacidade argumentativa é mais difícil porque, por exemplo, nós temos que reconhecer parcialmente que o impeachment é um dispositivo constitucional, mas todos sabem que algo além disso aconteceu. E a realidade está cheia de evidências, basta você ligar todos os jornais das quatro, cinco grandes famílias do país que passam uma outra história; os âncoras, até aqueles que a gente acha que exerce um certo distanciamento, tipo Boechat, que instituem a naturalidade do mundo que está aí pela forma de reconhecer o que foi instituído. Hoje de manhã mesmo ele falava do Temer reconhecendo que o Temer é o presidente; em nenhum momento ele disse: esse governo é provisório ou setores sociais contestam sua legitimidade. Falasse isso, pelo menos, para prezar um certo alinhamento com a realidade referida! Seria exercitar uma certa objetividade, porque há muitos setores sociais que contestam a legitimidade do Temer. Vejam bem, eu estou usando esse exemplo que não é o tema da nossa fala, mas vocês já sabem a minha posição também, que pode causar simpatias ou antipatias, mas nós não queremos unanimidade e o mundo é assim porque ele está em constante disputa.

Mas se nós transpusermos então esse domínio que eu chamo dos argumentáveis para esse debate, por exemplo, da transgenia e da agroecologia, ou para aquilo que nos dispusemos a vir aqui também trazer para reflexão, o domínio do conhecimento científico e o domínio do conhecimento não científico. Porque se a gente colocar no branco e no preto eles podem ser oposições e às vezes produzir antagonismos, mas se eu os colocar numa lógica Fuzzy aí, não a binária, zero e um, ou no famoso caminho do meio budista que está entre 0 e 1 , em qualquer intervalo possível entre o absoluto, entre o zero e o um. Mas se o espaço de intervalo foi estabelecido inicialmente como um limite, em uma escala de proporção, as coisas começam a se complicar mais.

Mas o que seria complementariedade? A complementariedade seria simplesmente juntar coisas diversas? Maçã com pera e dizer que são frutas, embora diferentes? Mas a maçã não tem nada a ver com a pera, ou com a laranja ou com o mamão. Cada uma é soberana na sua singularidade, mas nós convencionamos chamá-las de frutas. Então, as frutas unificariam intelectualmente, nominativamente, uma ordem diversa da realidade? O conhecimento científico, então, se ele for interpretado apenas na dimensão daqueles que operam com esse código, estaria interditando qualquer possibilidade de você incorporar no seu domínio aquilo que seria do domínio oposto, que seria da doxa ou da opinião. Eu vou dar um pequeno exemplo de uma seriedade não tanto acadêmica, mas que aconteceu na academia, num embate entre dois físicos nos Estados Unidos, Feynman e Murray Gell-Man, que escreveu O Quark e o Jaguar. São físicos quânticos e o Feynman era uma pessoa totalmente irreverente. Se tiverem oportunidade leiam, porque é um livro 
escrito por um aluno dele que se chama $O$ Arco-íris de Feynman, em que ele fala da história de vida do Feynman como físico; é um nome difícil porque combina consoantes, Mlodinow (eu gosto de ler muito essas coisas assim, bastante bizarras, pra sair um pouco da sisudez acadêmica; eu gosto de diversificar as minhas leituras. Isso me inspira muito e me salva às vezes de não ter que ser sempre rigidamente sistemático, pra não dizer monótono, no que faço e digo). É bem interessante porque o Feynman era uma pessoa carismática, que contestava muito a maneira como Murray fazia física. De tal maneira que pra se distanciar do estilo de Murray, ele criou signos, algoritmos diferentes da Física, ele fez uma contrafísica com outra nomenclatura, mas com sinais que não são difíceis de entender, como ele explica. Então, como ele se desentendia eternamente com Murray, um dia, ao encontrar-se com ele, disse: “você é um grego eu sou um babilônio!”. "Mas por que eu sou um grego?", disse Murray. "Porque você primeiro quer discutir, definir de antemão tudo conceitualmente, pra depois verificar se está correto aquilo que você está dizendo. Eu sou intuitivo como os babilônios; primeiro eu trabalho muito com a intuição pra verificar se essa intuição tem correspondência com a teoria". Então eu estou trazendo esse exemplo que é meio simplório e jocoso, mas que no fundo revela as possibilidades e as dificuldades de você estar operando com registros teóricos diferentes.

Aí nós estaríamos operando, possivelmente, com epistemologias meta ou paracientíficas, inclusive para justificar outras formas de produção do conhecimento, mais ou menos como a Isabelle Stengers vai fazer nas suas obras sobre cosmopolítica, quando ela vai discutir desde uma ecologia das práticas, uma ciência cidadã. Uma ciência pertinente, que eu chamaria de algo mais abrangente - usando uma expressão de um cientista inglês já falecido; ele era matemático e era filósofo também, que se chama John Ziman e ele vai trazer pra si a ideia de uma Ciência Pública. Provavelmente, aí nós estamos operando com uma epistemologia que a rigor não se satisfaz de estar discutindo ciência apenas dentro de alguns cânones internos, daquilo que é determinado pelos parâmetros que definem o que é ciência, que são vários. Pra vocês terem uma ideia de que realmente não há um único modelo, mesmo que seja definido por cientistas, mas há diversas concepções de ciência. Por isso nos obrigamos a operar com a ideia de fronteiras, de ciências híbridas.

É um pouco o que o Giddens nos seus ensaios vai dizer de uma maneira acertada, embora eu seja bastante crítico de algumas de suas teorias da globalização, mas ele é um autor respeitável por outros aspectos. Ele vai dizer o seguinte: quando as ciências sociais ganharam legitimidade lá pelo final do século XIX, que elas descobriram o seu objeto - todos nós que lemos Durkheim sabemos que Durkheim reivindicava ter um objeto próprio para a recém-criada sociologia, devendo então 
encontrar um objeto, quando ele disse ser o "fato social" o objeto da sociologia: para reafirmar seu credo no objetivismo, este fato social é exterior, é coercitivo, é impositivo, ele existe fora, independente de quem o observa, a exemplo dos objetos físicos e naturais. Assim, enquanto e quando as ciências sociais estavam ganhando essa legitimidade, eis que nas próprias ciências tomadas como referência por Durkheim e por Comte, alguns 50 anos antes (ciências físico-químicas, por exemplo) e socialmente legitimadas, eis que se instalam desacordos e dissensos, que foi o longo período do embate na física, a escola de Copenhague com a escola da teoria da relatividade, o que acabou trazendo reflexões bastante interessantes sobre essa relação sujeito e objeto. Os quânticos diziam que o observador sempre perturbava os átomos e os elétrons que nunca poderiam ocupar o mesmo lugar, então não poderia estar dizendo o que acontece, porque ora ele é matéria, ora ele é energia. Então como é que eu vou estabelecer algo fixo em relação ao objeto, e que a posição das partículas subatômicas depende sempre de medições, o que acabou sendo designado por Heisenberg como sendo "o princípio da incerteza", o que não quer dizer que as interações e posições dessas subpartículas atômicas não possam ser conhecidas e matematicamente expressas por equações. Vocês sabem que nessa ordem dos fenômenos das ciências físico-químicas, aquilo que não pode ser matematizado não é aceito como algo cientificamente estabelecido.

Essa discussão seria irrisória para as ciências humanas e sociais, sem grandes consequências no domínio que nós operamos. Isso não quer dizer que nós não tenhamos critérios. Quando vocês vão fazer suas dissertações, primeiro vocês recolhem todo o inventário do debate sobre os temas, então vocês estão reconhecendo que esses conhecimentos são pertinentes, são legitimados, e que vocês têm que passar por eles, pois sem os quais vocês não são reconhecidos pelos seus pares. Na banca vocês vão ser cobrados: "escuta, você descobriu a teoria ontem? Ninguém falou sobre seu tema? De que maneira foi falado? Aquilo que você quer estudar como é que você vai provar para a gente, que métodos que você vai utilizar, quais são os recursos operacionais, as técnicas de pesquisa que você vai usar para recolher amostra da realidade, interpretá-las e convencer de que seus resultados são significativos para aquela grande pergunta que você tem lá - se é que você conseguiu fazer a pergunta, porque as hipóteses são feitas no final". As grandes perguntas são feitas no final, e é normal, é necessário que seja assim, porque nós não somos tão conhecedores como a gente presume. Salvo se vocês operarem com a seguinte concepção de ciência: eu acredito nessas teorias que eu estou defendendo e se a realidade não se confirmar tanto pior para ela! Se vocês operarem com outros critérios, porque realmente...

Eu sempre falo, a partir de uma certa altura da minha vida, agora eu vou começar a ligar o "piloto automático"; talvez aí me aproximando do Feynman, porque o Feynman não falava isso... É 
como na pintura, não é?... O Picasso, quando ele usava o naïf da pintura (ingênua) africana, ele não começou pela arte naïve africana... Você olha um desenho dessa fase naïve do Picasso e diz: "ah! Isso minha filha de 5 anos também faz!”. Mas é preciso reconhecer também que Picasso dominava magistralmente a técnica da pintura em todas as suas fases de criação e ele era reconhecido por seus pares como um grande criador. Então, quando eu digo "piloto automático" implica - não que a gente faça grandes teorias e grandes achados - a intuição e a experiência devem estar acompanhadas de um embasamento e o "piloto automático" é aquele que não viola as leis da física, ele não viola o plano de voo, o plano de voo já está criptografado aí no "piloto automático"; ele interpreta as informações a partir do tempo e do espaço que ele está percorrendo, ele sabe aonde vai chegar e a que momento deve reduzir a velocidade e a altura para poder aterrissar. Pode dar problema no "piloto automático" também, evidente, talvez é da ordem do não explícito e de variáveis não contempladas na programação. Mas eu digo que com o tempo o nosso trabalho de pesquisa não precisa necessariamente ficar se afirmando permanentemente; aqui não está a grande questão. Às vezes a pessoa não que tenha preguiça, mas está implícito no seu percorrido que ela está buscando determinados aspectos que ela já inclui como válidos, e a intuição dela vai sendo fortalecida pela sua experiência de pesquisa. De tal maneira que é um processo complexo, a receita não funciona. Receitas muito fechadas criam distorções na pesquisa, de tal maneira que nós com a pesquisa estamos sempre nos transformando.

É um pouco aquilo que Wright Mills dizia sobre a imaginação sociológica, que deriva do processo particular de experiência, que você adquiriu no contato com as suas elucubrações com a teoria, no manejo que a gente faz das teorias ou aquilo que vocês vão se defrontando na experiência de pesquisa de campo e no debate que vocês fazem com seus pares, com os colegas, com os professores, orientadores etc.

Essa relação entre orientação e aluno é também bastante complexa; bastante complexa porque cada um tem suas estratégias e depende muito das idiossincrasias, da personalidade também, do professor e do aluno. E aí tem gosto pra tudo! Tem aquele professor que se o aluno não fizer de acordo com os autores os quais ele tem preferência intelectual, se ele é devedor de alguns autores e se você não ler os autores dele, você já é visto como fazendo o que você quiser. Então, pra gente é sempre um alerta. E também da relação do pesquisador com relação à orientação, às vezes são rebeldias justificáveis e às vezes são rebeldias injustificáveis. Então é uma relação complexa, mas tudo isso vai compondo um quadro bem interessante e que é constitutivo da própria experiência da pesquisa: como cada um lida com as teorias, como cada um lida com as experiências práticas da pesquisa e o agenciamento disso em termos de provocar efeitos novos. Porque uma coisa que talvez 
eu tenha aprendido algo com isso, "não confie muito nas certezas que você tem pelo menos até uma certa altura da pesquisa"; depois de um determinado momento da pesquisa, passa-se de uma incerteza quase geral para certezas provisórias, mesmo que sejam certezas relativas, ou seja, não absolutas, nos achados, nos insights, no processo de pesquisa. Enfim, acho que cada um é único como dizia o Sartre, cada ser humano vale por si e vale por todos, por si porque é singular, não há um único indivíduo igual ao outro, mas vale por todos porque nós todos pertencemos a determinadas faunas: à espécie humana, a nosso tempo, enfim, há muitas coincidências daquilo que somos, e no campo do trabalho acadêmico-científico, há regras e normas que são seguidas e que definem padrões reconhecíveis pela comunidade acadêmica e pelas sanções ou aprovações dos pares, que por sua vez produzem e reproduzem conhecimento acadêmico dentro de contextos culturais e sociais aceitos ou contestados por um bom número deles.

Então, pra fechar minha fala, eu me permitiria, em dois ou três minutos, refletir um pouco sobre esse domínio de um conhecimento instituído, da cultura científica na qual nós escrevemos, acadêmica e cientificamente, e do desenho institucional dessas agências que fazemos parte, que são não apenas essas nas quais vocês estão inseridos, mas da rede de relações que vocês estabelecem com todas as comunidades epistêmicas, sejam aquelas agências de controle - as agências fomentadoras da pesquisa, Capes, CNPq, Fundação Araucária, que são os agentes controladores e fomentadores que também traduzem dimensões de uma cartografia de poder da ciência e do conhecimento, com um conjunto de indicadores, a começar pelos vinculados a determinadas áreas de conhecimento disciplinar. Qual é a capacidade que a nossa área de conhecimento tem de alavancar recursos para pesquisa, por exemplo? Que tipo de produção a gente faz na hora da pesquisa e como nós socializamos esse conhecimento? Eu chamaria isso de usos sociais do conhecimento. E sobre esses dispositivos de gestão institucional, quais indicadores e critérios de qualificação e de seleção são utilizados? Critérios eminentemente corporativos, das comunidades e autoridades acadêmicas? Qual é o peso extracientífico, por exemplo, para avaliar a eficácia ou a relevância nos usos sociais desses conhecimentos?

Aí voltamos para Isabelle Stengers, isto é, se essa ciência é cidadã, se é pertinente, mesmo que ela seja produzida numa agência estatal como são as nossas universidades públicas. Da mesma maneira, outra pergunta que também deriva disso é: quão pública é essa ciência que nós produzimos? Quais são os mecanismos de contato de conexão que nós fazemos com o entorno social e se há uma cobrança social justamente sobre a nossa função, sobre a nossa atividade, que é educacional, mas também é uma instância de produção do conhecimento. Então esses são os desafios, que não são simples, pois dependem de desenhos institucionais que, por sua vez, 
dependem de uma discussão política sobre as agências do conhecimento e como a própria sociedade reconhece a sua importância.

Isso me faz lembrar também de alguns aspectos pitorescos sobre a existência e ampliação da rede de universidades, especialmente as particulares: eu tinha um aluno que era gestor de uma universidade privada em Curitiba, um economista, professor bem interessante, e nós estávamos discutindo a questão da economia ecológica. Um dia, numa conversa informal, ele disse: "Professor, você sabe qual é o maior problema das universidades particulares hoje no Brasil?". Eu disse: "O quê? Por exemplo, financiar pesquisa pra professor fazer seu doutorado fora, para formar grupo de pesquisa?”. Ele disse: “Não, isso não é o mais grave, porque existem as agências públicas estatais e o pessoal pode pegar bolsa do CNPQ pra ir pra fora. O maior problema da universidade particular é o tamanho do estacionamento! Pra você abrir uma universidade você tem que ter pelo menos três, quatro mil vagas para as pessoas estacionarem seus automóveis". É bastante cruel esta constatação! Felizmente aqui vocês têm o bicicletário, que é uma forma também indireta de dizer como nós exercitarmos a nossa mobilidade!

Enfim, eu tinha muitas coisas para dizer. Esse não era meu roteiro, meu script inicial; tinha um outro roteiro que eu queria falar um pouco do que nós estamos realizando hoje, em termos de pesquisa. Mas, enfim, eu acho que eu abriria então para uma conversa e daí talvez eu possa falar um pouco mais sobre o que estamos fazendo, e também de sua pertinência em termos de uma ecologia das práticas.

Texto recebido em 25/10/2016. Autor convidado. 